\title{
Reflexões sobre o Antropoceno, o paradigma da espécie humana e seu domínio ilusório sobre a Terra
}

doi) https://doi.org/10.21814/anthropocenica.3093

Resumo: Este ensaio compartilha reflexões sobre o Antropoceno de uma perspetiva ecológica e evolutiva da espécie humana. Parte-se da crise contemporânea da biodiversidade e da dinâmica e história da vida na Terra para contextualizar a sexta extinção em massa do Antropoceno, uma armadilha evolutiva que coloca em risco o seu próprio agente causador. A compreensão do "tempo profundo" geológico e evolutivo e dos cursos e percalços da história biótica evidenciam a vida como um imperativo da Terra. Esta perspetiva coloca o ser humano em posição de igualdade com qualquer outra espécie que já tenha florescido, no passado ou no presente, da evolução biológica. A origem evolutiva do espécie-centrismo humano é discutida e o antropocentrismo é apresentado como força motriz do Antropoceno. A crise sistémica do Antropoceno é posta como pressão de seleção cultural humana, que deve nortear-se pela sustentabilidade e pelo biocentrismo. Especula-se sobre o futuro evolutivo da jornada humana na Terra, a fixação de valores e princípios socioculturais e a necessidade de a humanidade contemporânea reconhecer-se como uma única tribo global que deve ser capaz de sustentar-se mutuamente.

Palabras-chave: Ecologia - Filosofia - Biocentrismo - Evolução cultural - Humanidade - H. Sapiens

Alexandre Túlio

Amaral

Nascimento

Departamento de

Engenharia Aplicada e Tecnologias Ambientais, Faculdade de Engenharia, Universidade do Estado de Minas Gerais Brasil

$\checkmark$ alexandre.nascimento@uemg.br

(iD) 0000-0002-4377-1513

\begin{abstract}
This essay shares reflections on the Anthropocene from an ecological and evolutionary perspective of the human species. It starts from the contemporary crisis of biodiversity and the dynamics and history of life on Earth to contextualize the sixth mass extinction of the Anthropocene, an evolutionary trap that puts its own causative agent at risk. The understanding of geological and evolutionary "deep time" and the courses and setbacks of biotic history highlight life as an imperative of the Earth. This perspective places the human being on an equal footing with any other species that has already flourished, in the past or in the present, from biological evolution. The evolutionary origin of the human centrism species is discussed and anthropocentrism is presented as the driving force of the Anthropocene. The systemic crisis of the Anthropocene is seen as pressure of human cultural selection, which must be guided by sustainability and biocentrism. There is speculation about the evolutionary future of the human journey on Earth, the setting of sociocultural values and principles and the need for contemporary humanity to recognize itself as a single global tribe that must be able to support each other.
\end{abstract}

Keywords: Ecology - Philosophy - Biocentrism - Cultural evolution - Humankind - H. Sapiens 


\section{Alexandre Túlio Amaral Nascimento}

\section{O Antropoceno e a sexta grande extinção}

O Antropoceno tem ao menos duas características marcantes: (i) os tecnofósseis das combinações sem precedentes de plásticos, fibras sintéticas, metais, concreto e pesticidas - dentre outros - na estratigrafia da Terra (Waters et al., 2016); e (ii) a crise de erosão da biodiversidade causada pela humanidade (Ceballos et al., 2015).

A influência combinada, interdependente e sinérgica do capitalismo a qualquer custo, do patriarcado oligárquico e do colonialismo estrutural entre norte e sul global têm levado, além da desigualdade social, ao colapso ambiental sistêmico, comprometendo a saúde ambiental e humana e alterando a dinâmica da biosfera. Os colapsos ecológicos em múltiplas escalas do Antropoceno têm em sua origem a extinção de espécies, o que vem acontecendo em um ritmo muito acelerado, deixando cada vez mais claro à ciência que estamos vivenciando o sexto evento de extinção em massa da história da Terra (Barnosky et al., 2011; Dirzo et al., 2014; Ceballos et al., 2015; Kolbert, 2015; Ceballos et al., 2020).

A extinção de uma espécie é um processo ecológico-evolutivo natural e inerente à história da vida (Benton, 1995). Contudo, as taxas naturais de extinção são muito baixas. Extinção e especiação equilibram-se quando há seleção natural e outros processos evolutivos operando no tempo ecológico e evolutivo. Espécies são extintas quando não se adaptam às mudanças no ambiente. Os indivíduos, suas populações e espécies podem tornar-se inaptos ao ambiente e incapazes de responder às suas pressões, especialmente, quando esses ambientes são perturbados e alterados abruptamente.

Ao tratar-se de "extinção de espécies" é importante não cair no risco de um raciocínio reducionista. Faz-se necessário compreender que espécies são o arranjo taxonómico mais fácil de contabilizar, mas que representam apenas uma das muitas dimensões da biodiversidade - que considera a diversidade biológica desde o nível genético e molecular dentro dos indivíduos e suas populações às interações entre espécies, comunidades e ao funcionamento dos ecossistemas e à dinâmica das paisagens (Noss, 1990; CDB, 1992; Begon et al., 2007, p. 602). A extinção de uma espécie repercute, em maior ou menor grau, em todos os níveis hierárquicos da biodiversidade e em seus atributos composicionais, estruturais e funcionais. Portanto, extinção é o gatilho inicial que altera o funcionamento e a estabilidade dos ecossistemas, inclusive nas grandes escalas temporais e espaciais que são mais relevantes para políticas e conservação (Isbell, et al., 2017). 
O big bang originou o universo há 13,8 bilhões de anos e a Terra constituiu-se há 4,5 bilhões de anos. O início da história biótica, por sua vez, data de cerca de 3,5 mil milhões de anos, quando assembleias de organismos procariotas (células sem núcleo definido) semelhantes às cianobactérias marcam os primeiros registros fósseis da vida (Schopf, 1993). Porém, foi apenas há cerca de 540 milhões de anos, no período Cambriano, que a vida se diversificou, passando a ocorrer registros de organismos representativos dos grupos biológicos ancestrais que deram origem à vida como a conhecemos. Desde então, eventos de extinção e especiação marcaram a história da vida na Terra, tornando a paleontologia importante aliada da estratigrafia e da geologia na datação geocronológica da história da Terra.

A documentação fóssil das taxas de extinção mostra que em cinco ocasiões elas se tornaram mais frequentes e expressivas nesses últimos 540 milhões de anos (Barnosky et al., 2011). Extinções em massa são caracterizadas como momentos em que a Terra perdeu entre $70 \%$ a $95 \%$ de suas espécies, em todos os ecossistemas do planeta e durante um intervalo de tempo geologicamente curto. Estas fases de extinções em massa transformaram o curso macroevolutivo da vida no planeta (Jablonski, 1986; Ridley, 2006, cap. 23).

A primeira grande extinção em massa aconteceu no final do Ordoviciano, há cerca de 444 milhões de anos atrás, quando a maioria das criaturas eram restritas ao ambiente marinho e oceânico. A última e quinta extinção em massa foi há cerca de 65 milhões de anos, marcando o fim dos dinossauros (os que não se tornaram aves) e do período Cretáceo e o início do Paleógénico. A maior de todas as extinções aconteceu entre esse percurso, há cerca de 252 milhões de anos, e eliminou até $96 \%$ das formas de vidas existentes, marcando a passagem do Permiano para o Triássico e a fronteira entre as eras Paleozoica e Mesozoica (Ridley, 2006).

As outras duas extinções em massa, a segunda e a quarta em ordem cronológica, aconteceram no final do período Devoniano e do Triássico, respetivamente, há cerca de 360 e 205 milhões de anos. Todas as cinco extinções em massa têm suas causas relacionadas a eventos naturais, como erupções vulcânicas, movimentos das placas tectônicas, mudanças do nível do mar e colisão com asteroides (Ridley, 2006, p. 658).

Estes eventos de extinção em massa, apesar de representarem breves momentos do tempo geológico, aconteceram durante o intervalo de alguns milhares ou até milhões de anos. A última extinção em massa - sem dúvidas a mais conhecida de todas devido ao carisma colossal dos dinossauros - foi a mais súbita e inesperada segundo os registros paleontológicos. Assim como os humanos, os dinossauros já reinaram absolutos e 


\section{Alexandre Túlio Amaral Nascimento}

dominaram a Terra durante mais de 150 milhões de anos, até que a maioria deles se extinguiu por não terem conseguido lidar com uma crise súbita desencadeada pela colisão de um meteoro com a Terra. Steve Brusatte (2019), em seu livro Ascensão e queda dos dinossauros, especula sobre as lições que esse evento marcante da história da Terra pode nos dar.

O Homo sapiens está em cena no palco evolutivo que é a vida na Terra há meros 300 mil anos (Hublin et al., 2017; Richter et al., 2017), nossos ancestrais hominídeos há cerca de apenas 6 milhões de anos. A sexta extinção em massa e as crises sistémicas do Antropoceno não nos deixam muito otimistas quanto às perspetivas de que possamos permanecer por muito mais tempo. Somos uma espécie jovem e com uma passagem que provavelmente será breve nessa contínua e dinâmica peça evolutiva da vida no grande teatro ecológico de possibilidades que é a Terra (Hutchinson, 1965). A não ser que haja profundas e complexas mudanças na forma de H. sapiens existir, consumir recursos e se relacionar com as demais espécies com as quais coabita e coexiste.

O diferente dessa sexta extinção é que ela é a primeira desencadeada por uma única espécie em particular, o Homo sapiens. Ironicamente, esse processo poderá levar à extinção da própria espécie humana. Esta armadilha evolutiva é o que há de mais curioso nesta sexta extinção em massa, o seu agente causador pode vir a ser vítima do seu próprio estrago. Seremos capazes de evitar esse dilema, abrandando e revertendo a sexta grande extinção?

Esta noção do "tempo profundo" geológico e evolutivo e dos cursos e percalços da história biótica evidenciam a vida como imperativo da Terra. Ela sempre se reinventa e sua árvore se regenera em novos galhos e troncos evolutivos. Esta perspetiva deixa claro que não haveria muita diferença entre a extinção dos tiranossauros, dos mamutes, das preguiças gigantes ou das ararinhas azuis e a extinção da espécie humana. Certamente, não faríamos falta à Terra.

\section{O espécie-centrismo humano e seu domínio ilusório sobre a Terra}

O espécie-centrismo humano não se fundamenta. O nosso controlo e domínio sobre o planeta e a natureza são pura ilusão. As extinções em massa e a história da vida deixam claro que a Terra não é frágil, mas a nossa posição nela é. A natureza não nos pertence, nós é que pertencemos a ela. Como qualquer outra espécie que habita ou já tenha habitado esse planeta, somos frutos de um acidente evolutivo, produtos da mutação 
aleatória e da série de acasos da seleção natural. Também, como quaisquer outras espécies, influenciamos e somos influenciados pelo ambiente em que estamos e pelas espécies com as quais interagimos e interdependemos.

A pandemia de COVID-19 é didática em expor a interdependência e fragilidade de nossa espécie. Frente ao choque de realidade biológica dado pela pandemia do coronavírus a humanidade tem a oportunidade de rever a sua trajetória civilizacional e a sua influência massivamente deletéria e desestabilizadora na teia da vida que é a biosfera terrestre (Santos, 2020). O caráter pedagógico da pandemia também tem demonstrado que, como espécie, partilhamos de um mesmo destino comum (Safatle, 2020; Santos, 2020).

Edward Wilson, um dos mais consagrados e importantes biólogos dos nossos tempos, refere-se ao Antropoceno como uma "era de e para apenas uma espécie, à qual todo o restante da vida está subordinada", e chama-lhe Eremoceno - a era da solidão (Wilson, 2018, p. 96). Entretanto, a subordinação que Homo sapiens impõe às demais espécies negligencia que as forças da natureza e a interdependência biológica estão além da nossa capacidade de controle e domínio (Wallace-Wells, 2019, p. 189).

As bases biológicas desse espécie-centrismo cultural estariam no aprimoramento da inteligência social e no favorecimento da sobrevivência dos indivíduos e seus grupos (Damásio, 2018; Wilson, 2018). Esse comportamento espécie-centrado é herança evolutiva que no Homo sapiens resultou no interesse intraespecífico narcísico e na curiosidade insaciável, que parecem ser a chave de nossa genialidade e sucesso demográfico (Harari, 2015; Mlodinow, 2015; Wilson, 2018) - 96\% do peso dos mamíferos mundiais são constituídos por humanos e seus animais de estimação e criação (Bar-On et al., 2018). A curiosidade e a criatividade humanas, propulsoras do nosso sucesso como espécie, estão alicerçadas na vida e na sua determinação e comando precisos de resistir e auto-projetar-se no futuro a qualquer custo (Damásio, 2018, p. 42).

Somos viciados em interações e conflitos tribais, o que se reflete nas religiões, ideologias, política, clubes desportivos e conflitos étnicos. Temos uma disfunção, intrínseca à nossa espécie, que confere miopia e incómodo em cooperar e integrar com os que são alheios à nossa tribo (Darwin, 1871; Damásio, 2018). Isso agrava-se e a miopia transforma-se em cegueira necro-utilitarista quando consideramos as nossas relações com as outras espécies coexistentes connosco - especialmente após a revolução agrícola há cerca de 12 mil anos, quando deixámos de ser caçadores-recolectores e rompemos os limites de capacidade de carga do ambiente, passando a dominá-lo (Harari, 2015). Pelo acumular de poder e riqueza dos nossos núcleos sociais e identitários, nós simplesmente 


\section{Alexandre Túlio Amaral Nascimento}

ignoramos o legado evolutivo da vida e seus princípios de interdependência, complexidade, dinamismo e limiares de resiliência.

Apesar das religiões e do egocentrismo humano irem na direção contrária, a ciência não nos dá nenhuma explicação sobrenatural para o sentido da existência da espécie humana. Reconhecermos definitivamente a nossa modesta origem evolutiva e nosso alto grau de parentesco com todas as formas de vida, fruto presente ou histórico desse processo é um passo importante e decisivo, que já poderia ter sido melhor incorporado na sociedade nos últimos 160 anos - considerando-se a publicação conjunta dos artigos de Darwin e Wallace na Sociedade Lineana de Londres em 1858 e o lançamento de $A$ origem das espécies em 1859. O Antropocentrismo precisa urgentemente dar lugar ao biocentrismo.

Genes e memes são, respetivamente, as unidades de seleção biológica e cultural (Dawkins, 2007). A seleção multinível - difundida pelos biólogos evolucionistas Edward Wilson e David Wilson - entende que DNAs, indivíduos e grupos são veículos para os genes, sendo afetados pela seleção individual (egoísta e competitiva) e pela seleção de grupo (altruísta e cooperativa). Um místico ou religioso diria, incorrendo numa simplificação extrema e reducionista, que a primeira favorece o pecado e a vaidade e a segunda a virtude e a empatia.

O conflito entre esses instintos é identitário de muitas espécies, mas a sua consciência psíquica e compreensão parecem característicos da condição humana. Em espécies eussociais, como formigas, abelhas, vespas e cupins, ainda que totalmente moldadas pela seleção de grupo (Wilson \& Hölldobler, 2005), essa consciência não existe. Parece que fomos, evolutivamente, perdendo a capacidade de comunicação bioquímica e por feromonas inata a tantas espécies, inclusive de microrganismos e fungos, às custas de uma comunicação mais autocentrada, promotora de complexidade cultural e social (Wilson, 2018).

Somos frutos desse misto de evolução biológica e cultural que resultou na fascinação ilimitada que temos por nós mesmos, fazendo do antropocentrismo a força motriz do Antropoceno (Wilson, 2018). A questão posta é: o horizonte de crises, catástrofes e colapsos, característicos dessa nova época, seriam capazes de fazer do antropocentrismo um antídoto endógeno que nos pressionaria ao biocentrismo, ao bem viver e à sustentabilidade? 


\section{O paradigma humano}

Até aqui, a evolução cultural humana fixou padrões que boicotaram o facto biológico de sermos uma espécie como qualquer outra, fruto dos mesmos processos evolutivos, igualmente por eles regidos. O Antropoceno, mais que uma nova época geológica - que apesar de ainda estar em vias de ser oficialmente reconhecida pela União Internacional das Sociedades de Geologia já é amplamente difundida na comunidade académica e científica - representa um marco epistémico transdisciplinar no século 21, que pressiona mudanças complexas e profundas no modus operandis da humanidade existir. A crise sistémica do Antropoceno expõe a vulnerabilidade da espécie humana à extinção, como qualquer outra espécie.

Se a extinção de espécies é parte da dinâmica ecológica-evolutiva da vida, por que é que com o Homo sapiens seria diferente? É possível manter o nosso estilo de vida espécie-centrada e regido pela religião do crescimento económico infinito? A crise climática, o colapso dos ecossistemas em múltiplas escalas, pandemias, dentre outros reflexos da crise civilizacional contemporânea, são pressões evolutivas capazes de gerar mudanças efetivas no padrão de seleção cultural de $H$. sapiens? As possibilidades de integração de algoritmos de inteligência artificial com algoritmos bioquímicos e com a biotecnologia levar-nos-ão a espécies pós-humanas de um pós-Antropoceno ? A busca por respostas a perguntas como estas têm norteado muito do debate acerca do Antropoceno e do pensamento científico contemporâneo.

Avanços científicos, tecnológicos e da biologia sintética sempre causam otimismo e podem ser importantes aliados, porém, será preciso ter cuidado para não cairmos na recorrente armadilha do autoengano e do negacionismo. Não cabe mais a ilusão de que a nossa tecnologia e inventividade sempre nos garantirão qualidade de vida e prosperidade. Nenhum aliado tecnológico terá valia se o Homo sapiens não mudar a sua forma de ser, existir e consumir.

Se o que nos diferencia das outras espécies é a nossa cognição, humanidade, cultura, intelecto, ciência e conhecimento das mais diversas áreas e saberes, tão recentemente construídas na história humana, pode dizer-se então que o que nos diferencia é nosso cérebro e toda evolução cultural que nele é processada (Wilson, 2018).

A forma como nosso cérebro, esse intricado regente da complexidade humana, processará a crise do Antropoceno urge por fixar padrões culturais compatíveis com o biocentrismo, com a sustentabilidade e com o conhecimento científico. O Antropoceno é também um apelo para que a humanidade respeite a ciência e o tempo dos cientistas. A 


\section{Alexandre Túlio Amaral Nascimento}

máxima de Raymond Williams (2011) de que todas as crises humanas são crises de compreensão assenta bem à crise civilizacional do Antropoceno. Enquanto não compreendermos que evidências e factos científicos - como o aquecimento global, a crise climática, a extinção em massa e a interdependência biológica - são independentes da nossa opinião, ignorância ou negligência, a humanidade continuará postergando o problema e as formas de mitigá-lo.

Se a ciência fosse considerada da forma como deveria, não teríamos chegado ao ponto a que chegámos. Há consenso, há pelo menos 50 anos, de que o $\mathrm{CO}_{2}$ agrava o efeito estufa e modelos climáticos que anunciam, preveem e acertam o aquecimento global e a crise climática. Ainda assim, o século XX ergueu-se sobre a indústria petroquímica, termoelétrica e da queima de combustíveis fósseis, dando espaço à soberania de grandes corporações e fazendo com que os interesses privados e de mercado, frequentemente, se sobreponham aos interesses públicos e do bem-comum.

Assim, o sistema democrático tem sido muito comumente cooptado pelas grandes corporações e pelos interesses privados, boicotando a ciência em benefício de muito poucos e às custas de toda sorte de impactos ambientais, desigualdade social e concentração de renda. Temos uma ciência robusta que poderia subsidiar políticas e governança muito mais afins à sustentabilidade. Porém, há obscurantismo e negacionismo crescentes, não só dos cidadãos, mas também de muitos governos.

Ciência e democracia devem guiar-nos. Ambas têm valores afins ao debate livre, encorajam opiniões não convencionais e a diversidade, visando o intercâmbio de ideias e o avanço do conhecimento. Ambas não têm verdades absolutas, mas precisam reconhecer os erros do caminho e guiarem-se por padrões rigorosos de evidências, coerência e honestidade (Sagan, 2006, p. 59). Política, democracia e ciência são as principais armas que temos contra a barbárie, a desconstrução e a crise imposta e crescente do Antropoceno. A conexão entre ciência e democracia deve valer-se das tecnologias de comunicação digital, do big data, da internet das coisas e da inteligência artificial em favor do fortalecimento de sua transparência, representatividade, inclusão e envolvimento da população.

A tríade ciência-democracia-sustentabilidade precisa levantar voo depressa. Há indícios de que esta terceira década do século 21, entre os anos 2020 e 2030, será decisiva para que a humanidade acerte o seu passo evolutivo e reverta os seus impactos massivos e o seu caminho evolutivo sobre a Terra. Caso contrário, limiares de resiliência ecológica do Sistema-Terra poderão ser rompidos, levando-nos em direção a extremos climáticos de temperatura e imprevisibilidade jamais vivenciados em nossa jornada evolutiva ou dos 
nossos ancestrais hominídeos (Steffen et al., 2018; Bertolami \& Francisco, 2019; Veiga, 2019).

Para que levantemos voo neste século e no Antropoceno é preciso desconstruir a lógica de progresso desenvolvimentista do lucro a qualquer custo e contra a diversidade da vida, que favorece desigualdades e crises ecológicas. Tratados e pactos globais - como o Acordo de Paris, os Objetivos de Desenvolvimento Sustentável (ODS) e sua Agenda 2030 - só se farão cumprir à medida que a governança do desenvolvimento e a governança do meio ambiente e da sustentabilidade se alinharem numa mesma e única direção (Veiga, 2017), orientada pelo bem viver, pelo decrescimento do norte global e pelo pósextrativismo do hemisfério sul, buscando romper vícios geopolíticos e económicos que têm acelerado o vórtex da sexta extinção em massa e das crises que dela decorrem (Acosta, 2016; Acosta \& Brand, 2018; Solón, 2019).

Princípios como os de sustentabilidade, interdependência, coexistência, complexidade e resiliência precisam ser assimilados como valores culturais e sociais dominantes no Antropoceno. Assim como a diversidade genética é a matéria prima para a seleção natural e evolução biológica, a diversidade cultural deve ser reconhecida como vital para a sustentabilidade e viabilidade da espécie humana no Antropoceno, tornandose necessário romper a hegemonia da cultura ocidental e valorar os etnosaberes dos povos originários. Essas utopias são horizontes necessários frente a tantas distopias desses tempos.

Esses paradigmas da humanidade dependem, como já foi dito, de uma integração necessária, ainda que tardia, entre ciência e democracia. Esse desafio faz-se ainda maior em países tropicais e megabiodiversos, como o Brasil, que além da extrema desigualdade socioeconómica, precisa libertar-se da lógica neoliberal e neoextrativista para que possa valer-se da sua vocação de biodiversidade e desenvolver o seu potencial em bioeconomia e sustentabilidade.

A transformação precisa ser do micro para o macro, do individual para o coletivo, do privado para o público, do local para o global, passando pela geopolítica e por um sentido de cidadania e bioética, de pessoas físicas e jurídicas, que precisam agir com muito mais responsabilidade e proatividade. Alternativas não podem ficar vinculadas às crises pandémicas e aos desastres ambientais depois destes já terem acontecido. A ciência tem vindo a alertar há décadas, e avisa com ênfase cada vez maior: Não temos muito tempo! A mudança é para ontem! É para já! (Kolbert, 2015; Marques-Filho, 2016; Steffen et al., 2018; Wallace-Wells, 2019; Amigo, 2020). 


\section{Alexandre Túlio Amaral Nascimento}

É preciso ação, inovação, integração e adaptação. As velhas máximas ambientalistas de reciclar, reutilizar e reduzir já não são suficientes e torna-se necessário valermo-nos de muitos outros erres: repensar, recusar, reconceptualizar, reestruturar, redistribuir, reconfigurar, restaurar e revolucionar.

A tribo humana do Antropoceno é única, global, interconectada e interdependente, como ficou escancarado nesse histórico ano de 2020 com a pandemia de COVID-19. Devemos sustentar-nos mutuamente num corpo social e político regido pelo bem viver e pela sustentabilidade (Safatle, 2020). Este sentido de coletividade e ética global deve estender-se a todas as espécies que connosco existem nesse "pálido ponto azul" a pairar na imensidão cósmica.

Esse recado da ciência à sociedade não tem nada de novo. Há 25 anos atrás, por exemplo, o célebre cientista e pioneiro na divulgação científica, Carl Sagan, já nos dizia em seu livro $O$ mundo assombrado pelos demônios que «quando as fraquezas que sempre tivemos se unem a uma capacidade de causar dano numa escala planetária sem precedentes, algo mais é exigido de nós - uma ética emergente que também deve ser estabelecida numa escala planetária sem precedentes» (Sagan, 2006, p. 323).

A ecologia e a evolução trazem-nos algum otimismo ao mostrar que pressões seletivas podem levar a mudanças impressionantes na história evolutiva das interações ecológicas entre os organismos que nela estão envolvidos. A coevolução é como um bailado evolutivo de um para lá e muitos para cá ou como uma corrida armamentista adaptativa e reativa das espécies, e o resultado dessa dinâmica pode ser muitas vezes surpreendente. A jornada humana na Terra desafia-nos a uma dessas grandes mudanças - de parasitas a simbiontes da biosfera terrestre, pressionados por seleção cultural, decorrente das crises sistémicas, pandemias, catástrofes, aquecimento global e crise climática. A ecologia e a evolução também ensinam com muita clareza: quem não se adapta às pressões do ambiente e às mudanças é extinto, às vezes num piscar de olhos do tempo evolutivo ou geológico.

\section{Bibliografia}

Acosta, A. (2016). O bem viver: uma oportunidade para imaginar outros mundos. São Paulo: Editora Elefante. 
Acosta, A. \& Brand, U. (2018). Pós-extrativismo e decrescimento: saídas do labirinto capitalista. São Paulo: Editora Elefante.

Amigo, I. (2020) The Amazon's Fragile Future. Nature, 578, pp. 505-507. https://media.nature.com/original/magazine-assets/d41586-020-00508-4/d41586-02000508-4.pdf?fbclid=IwAR10iyWZMfqQ13nyk9wkto5GDFzIBzqkGcVUfMb3YbgopwU9s4_9OyvvMo

Bar-On, Y., Phillips, R. \& Milo, R. (2018). The biomass distribution on Earth. PNAS 115(25), pp. 6506-6511.

Barnosky, A. D., Matzke, N., Tomiya, S., Wogan, G. O., Swartz, B., Quental, T. B., Marshall, C., McGuire, J. L., Lindsey, E. L., Maguire, K. C., Mersey, B., \& Ferrer, E. A. (2011). Has the Earth's sixth mass extinction already arrived? Nature, 471(7336), 51-57.

Begon, M., Harper, J. \& Townsend, C. (2007). Ecologia: de Indivíduos a Ecossistemas. 4. ed. Porto Alegre: Artmed.

Benton M. J. (1995). Diversification and extinction in the history of life. Science (New York, N.Y.), 268(5207), 52-58. https://doi.org/10.1126/science.7701342

Bertolami, O. \& Francisco, F. (2019). A physical framework for the earth system in the Anthropocene: towards an accountancy system. In J. Mendes \& B. Sylla (Eds.), EIBEA 2019. Encontro Iberoamericano de Estudos do Antropoceno. Atas (pp. 41-52). Braga. Portugal. http://repositorium.sdum.uminho.pt/handle/1822/62541

Brusatte, S. (2019). Ascensão e queda dos dinossauros: uma nova história do mundo perdido. $1^{\text {a }}$ ed. São Paulo: Record.

CDB. (1992). Convenção Internacional Sobre a Diversidade Biológica. Conferência das Nações Unidas sobre Meio Ambiente e Desenvolvimento. Rio de Janeiro. https://www.mma.gov.br/informma/item/7513-convencao-sobre-diversidade-biologica$\mathrm{cdb}$ 


\section{Alexandre Túlio Amaral Nascimento}

Ceballos, G., Ehrlich, P., Barnosky, A., García, A., Pringle, R. \& Palmer, R. (2015). Accelerated modern human-induced species losses: Entering the sixth mass extinction. Science Advances, 1(5). https://advances.sciencemag.org/content/1/5/e1400253

Ceballos, G., Ehrlich, P. \& Raven, P. (2020). Vertebrates on the brink as indicators of biological annihilation and the sixth mass extinction. PNAS, 117(24), pp. 13596-13602.

Damásio, A. (2018). A estranha ordem das coisas: as origens biológicas dos sentimentos e da cultura. $1^{a}$ ed. São Paulo: Companhia das Letras.

Darwin, C. (1871). Descent of Man. Londres: John Murray.

Dawkins, R. (2007). O gene egoísta. Trad. Rejane Rubino. São Paulo: Companhia das Letras.

Dirzo, R., Young, H., Galetti, M., Ceballos, G., Isaac, N. \& Collen, B. (2014). Defaunation in the Anthropocene. Science, 345(6195), pp. 401-406. https://science.sciencemag.org/content/345/6195/401

Harari, Y. (2015). Sapiens - uma breve história da humanidade. $8^{a}$ ed. Porto Alegre: RS: L\&PM.

Hublin, J.-J., Ben-Ncer, A., Bailey, S. E., Freidline, S. E., Neubauer, S., Skinner, M. M., Bergmann, I., Le Cabec, A., Benazzi, S., Harvati, K., \& Gunz, P. (2017). New fossils from Jebel Irhoud, Morocco and the pan-African origin of Homo sapiens. Nature, 546(7657), pp. 289-292.

Hutchinson, G. (1965). The ecological theater and the evolutionary play. New Haven, CT: Yale University Press.

Isbell, F., Gonzalez, A., Loreau, M., Cowles, J., Díaz, S., Hector, A., MacE, G. M., Wardle, D. A., O'Connor, M. I., Duffy, J. E., Turnbull, L. A., Thompson, P. L., \& Larigauderie, A. (2017). Linking the influence and dependence of people on biodiversity across scales. Nature, 546(7656), 65-72. 
Jablonski, D. (1986). Background and Mass Extinctions: The Alternation of Macroevolutionary Regimes. Science, 231(4734), pp. 129-133. https://science.sciencemag.org/content/231/4734/129?ijkey=2f1b812a32bb0a8b2cc9246 91a699dd9cb7de575\&keytype2=tf_ipsecsha

Kolbert, E. (2015). A Sexta Extinção: uma história não natural. $1^{\text {a }}$ edição. Tradução Mauro Pinheiro. Rio de Janeiro: Editora Intrínseca.

Mlodinow, L. (2015). De primatas a astronautas: a jornada do homem em busca do conhecimento. $1^{\text {a }}$ ed. Rio de Janeiro: Zahar.

Marques-Filho, L. (2016). Capitalismo e colapso ambiental. $2^{\text {a }}$ ed. rev. e ampl. Campinas, SP: Editora da Unicamp.

Noss, R. (1990). Indicators for Monitoring Biodiversity: A Hierarchical Approach. Conservation Biology, $\quad 4, \quad$ pp. 355-364. https://conbio.onlinelibrary.wiley.com/doi/10.1111/j.1523-1739.1990.tb00309.x

Ridley, M. (2006). Evolução. 3a ed. Porto Alegre: Artmed.

Richter, D., Grün, R., Joannes-Boyau, R., Steele, T. E., Amani, F., Rué, M., Fernandes, P., Raynal, J. P., Geraads, D., Ben-Ncer, A., Hublin, J. J., \& McPherron, S. P. (2017). The age of the hominin fossils from Jebel Irhoud, Morocco, and the origins of the Middle Stone Age. Nature, 546(7657), 293-296.

Sagan, C. (2006). O mundo assombrado pelos demônios: a ciência vista como uma vela no escuro. Trad.: Rosaura Eichenberg. São Paulo: Companhia das Letras.

Santos, B. (2020). A cruel pedagogia do vírus. São Paulo: Editora Boitempo.

Safatle, V. (2020). Bem-vindo ao Estado suicidário. Jornal GG. https://jornalggn.com.br/blog/doney/bem-vindo-ao-estado-suicidario-por-vladimirsafatle-n-1-edicoes 


\section{Alexandre Túlio Amaral Nascimento}

Schopf, J. (1993). Microfossils of the Early Archean Apex chert: new evidence of the antiquity of life. Science, New Series, 260(5108), pp. 640-646.

Steffen, W., Rockström, J., Richardson, K., Lenton, T. M., Folke, C., Liverman, D., Summerhayes, C. P., Barnosky, A. D., Cornell, S. E., Crucifix, M., Donges, J. F., Fetzer, I., Lade, S. J., Scheffer, M., Winkelmann, R., \& Schellnhuber, H. J. (2018). Trajectories of the Earth System in the Anthropocene. Proceedings of the National Academy of Sciences of the United States of America, 115(33), 8252-8259.

Solón, P. (2019). Alternativas sistêmicas: bem viver, decrescimento, comuns, ecofeminismo, direitos da mãe Terra e desglobalização. Organização Pablo Solón. São Paulo: Editora Elefante.

Veiga, J. (2019). O Antropoceno e a ciência do sistema Terra. São Paulo: Editora 34.

Veiga, J. (2017). A primeira utopia do Antropoceno. Ambiente \& Sociedade, 20(2), p. 233252.

Wallace-Wells, D. (2019). A Terra Inabitável: uma história do futuro. $1^{\mathrm{a}}$ edição. Tradução Cássio de Arantes Leite. São Paulo: Companhia das Letras.

Waters, C. N., Zalasiewicz, J., Summerhayes, C., Barnosky, A. D., Poirier, C., Gałuszka, A., Cearreta, A., Edgeworth, M., Ellis, E. C., Ellis, M., Jeandel, C., Leinfelder, R., McNeill, J. R., Richter, D. d., Steffen, W., Syvitski, J., Vidas, D., Wagreich, M., Williams, M., Zhisheng, A., ... Wolfe, A. P. (2016). The Anthropocene is functionally and stratigraphically distinct from the Holocene. Science (New York, N.Y.), 351(6269), aad2622.

Williams, R. (2011). Cultura e Sociedade: De Coleridge a Orwell. Trad.: Vera Joscelyne. São Paulo: Editora Vozes.

Wilson, E. (2018). O sentido da existência humana. $1^{a}$ ed. Trad.: Érico Assis. São Paulo: Companhia das Letras.

Wilson, E.; Hölldobler, B. (2005). Eusociality: Origin and consequences. PNAS 102(38), pp. 13367-13371. 
Reflexões sobre o Antropoceno, o paradigma da espécie humana e o seu domínio ilusório sobre a Terra

Para citar:

Nascimento, A. T. A. (2020). Reflexões sobre o Antropoceno, o paradigm da espécie humana e seu domínio ilusório sobre a Terra. Anthropocenica. Revista de Estudos do Antropoceno e Ecocrítica 1: pp. 55-69. 